\title{
Fuzzy algorithm implementation in microcontroller for DC motor control
}

\author{
K. D. Atar ${ }^{1}$, C. B. Patil ${ }^{2}$, R. R. Mudholkar ${ }^{3}$ \\ ${ }^{1 *}$ Department of Electronics, The New College, Kolhapur, Maharashtra, INDIA,, \\ ${ }^{2}$ Department of Electronics, D. K. A. S. C. College, Ichalkaranji, Maharashtra, INDIA \\ ${ }^{3}$ Department of Electronics, Shivaji University, Kolhapur, Maharashtra, INDIA \\ *Corresponding Author: e-mail: attar.khwaja@gmail.com, Tel+919921825784 \\ ORCID iDs: http:/orcid.org/0000-0002-4203-4482 (Atar)
}

\begin{abstract}
In industrial automation, motor control technique plays the vital role. Motor consists of inductor or electromagnet. Causing inductor or electromagnet, magnetic inductions are produces which resists any change of motor speed. Hence, according to set point, precise speed control is challenging. However, using various control technique can be controls the speed of DC motor. The aim of the present paper is to implement hardware and control the speed of DC motor using embedded fuzzy logic. Set point have been applied externally and recorded the speed of motor through opto-isolator sensor module. In the hardware of DC motor control keypad, 2x16 LCD, DC motor driver and opto-isolator module are interfaced to PIC microcontroller. The Fuzzy algorithm is embedded in the microcontroller wherein input fuzification signals 'error $(\Delta \mathrm{e})^{\prime}$ ' and 'change in error $(\mathrm{e}(\mathrm{n}))^{\text {' }}$ and output fuzification signal 'PWM'. The both of inputs of fuzzy algorithm are varied and record output of fuzzy algorithm which is PWM. Moreover, the hardware implementation has been tested for real time control of DC Motor.
\end{abstract}

Keywords: Fuzzy algorithm, Speed control, PIC microcontroller, Hardware implementation

DOI: http://dx.doi.org/10.4314/ijest.v13i3.1

Cite this article as:

Atar K.D., Patil C.B., Mudholkar R.R. 2021. Fuzzy algorithm implementation in microcontroller for DC motor control. International Journal of Engineering, Science and Technology, Vol. 13, No. 3, pp. 1-9. doi: 10.4314/ijest.v13i3.1

Received: February 15, 2016; Accepted: February 18, 2017; Final acceptance in revised form: June 13, 2021

\section{Introduction}

DC motor is designed to convert direct current electrical energy to mechanical energy which works on the principle of electromagnetism. According to the applications of DC motors, it is available in different types, dimensions and sizes. As small motors can be used for toys, tools and home appliances while larger one can be used for elevator, vehicle and industries. DC motor driving system is an indispensable part of industrial applications like actuation and robotics, where speed control is required. DC motors are preferred for various control systems, due to their potential ability in applications involving high torque, speed and position control. In wide variety of applications of DC motor, we have to control the speed of motor. Because of inductive and magnetic effects of motor, its control is critical. For precision control of DC motor is the challenging for researcher. As compared conventional controllers, Fuzzy controller provides smooth output (Goel et al., 2012). For controlling of DC motor, different controllers can be used however here the embedded fuzzy control have been used.

The characteristics of DC motor pertaining to the performance and efficiency are suitable for many speed and position control systems (Meha et al., 2011). Pulse Width Modulation (PWM) is a technique used for switching a device (MOSFET) with reference to analog signal. DC motor speed control system is a complex nonlinear control system, because of the various parameters influence each other (Nanda and Crow, 1995). Fuzzy logic approach is to make decisions based on 'degrees of truth' rather than 
the modern computer, which is based on usual ' 0 or 1' Boolean logic. Fuzzy logic seems closer to the way our brain works (Zadeh, 1965). Fuzzy logic is followed by three steps: fuzzification, fuzzy inference and defuzzification. Average Weighted Defuzzification (AWD) method finds the resultant PWM count. Harb and Smadi (2009) have reported the performance improvement in dc motor using fuzzy logic controller. Yan et al. (2012) have designed PID and fuzzy PID controller in MATLAB for DC motor speed control application. They have studied the performance of PID and fuzzy-PID controllers. Ramadan et al. (2014) have proposed a FPGA based DC fuzzy logic motor control. (Pravadalioglu, 2005) has designed the Simulink model of PI and fuzzy model in MATLAB and studied the performance of dc motor. Lim (1995) has implemented the fuzzy PID controller and examined the real-time experimental study of DC motor. Hanamane et. al. (2006) proposed the temperature control using microprocessor. He has provided the set point temperature and studied the performance of heater using fuzzy logic.

In the present paper, the Mamdani's Inference method is employed for controlling the DC motor speed. The embedded ' $\mathrm{C}$ ' code is written for Programmable Interface Controller (PIC) 16F877A wherein two inputs one output fuzzy logic controller (FLC) with Mamdani's Inference method. In Embedded ' $\mathrm{C}$ ' code input parameter 'error' and 'change in error' is calculated which help to increasing the degree of accuracy. However for fuzzy logic the degrees of truth: $\omega_{1}, \omega_{2}, \omega_{3}$ and $\omega_{4}$ are finds then it is used for computation of PWM. The generated PWM is applied to FET for driving of DC motor. The opto-isolator sensor module is used to measure the RPM of DC motor. The measured RPM is provided to PIC microcontroller as an input.

\section{Block Diagram DC Motor Control System}

The output of opto-isolator sensor module is present speed of motor while the output of keypad is set point value. Present speed $(\mathrm{R})$ of the DC motor and set point (S) are applied to the ADC channels $\mathrm{A}_{1}$ and $\mathrm{A}_{2}$ of PIC microcontroller. 'Error ( $\mathrm{e}_{(\mathrm{n})}$ )' is the difference between present speed $(\mathrm{R})$ and set point $(\mathrm{S})$. According to 'previous error' (Stored error $\left.\mathrm{e}_{(\mathrm{n}-1)}\right)$ and 'error (e $\left(\mathrm{e}_{(\mathrm{n})}\right)$ ', finds the 'change in error $(\Delta \mathrm{e})$ '. The fuzzy algorithm is developed for two inputs $\left(\mathrm{e}_{(\mathrm{n})}\right.$ and $\Delta \mathrm{e}$ ) and one output (PWM count) system which is embedded in microcontroller in the form of code. When change in input occurs the fuzzy logic algorithm generates appropriate PWM count in the microcontroller. The generated counts are stored in corresponding resistor (CCPR1L) of microcontroller which is used for motor driver FET to control the speed of DC motor as shown in Figure 1.

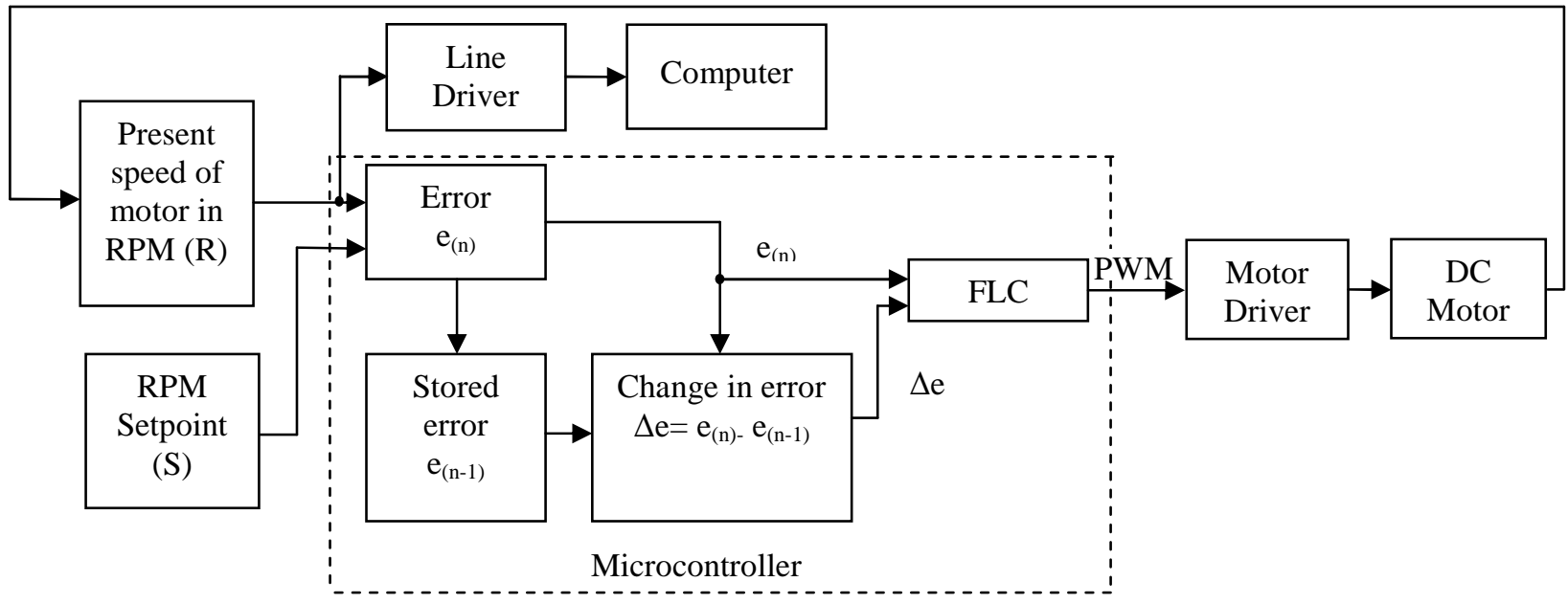

Figure 1. Block diagram of fuzzy based DC motor control system

\section{Circuit Diagram Explanation of DC Motor Control System}

A 5-volt power supply is constructed for source voltage of control system. The three reset keys are interfaced to PIC 16F877A microcontroller. Out of these one key is used for resetting the circuit and other two keys are used for making of set point while it is operating as an increment and decrement logic. The OS25B10 sensor is a high performance photo interrupter consisting of light emitting diode and high sensitive phototransistor. Utilization of this sensor is for measurement of fan speed while it is considered as one input. The generated PWM through microcontroller is applied to the gate of the MOSFET IRF540 for switching. FET is works like a driver. The DC motor connected between Vcc and drain of the MOSFET and source terminal of MOSFET is connected to ground however, PWM is applied to gate of MOSFET as shown in Figure 2. In this type of circuit connection the motor speed is depends on PWM which is applied to the gate of driver. The LCD 2x16 is interfaced to microcontroller for displaying of set point, and present motor speed. The set point, PWM and present motor speed is also send to computer through $\max 232$ for further reference. 


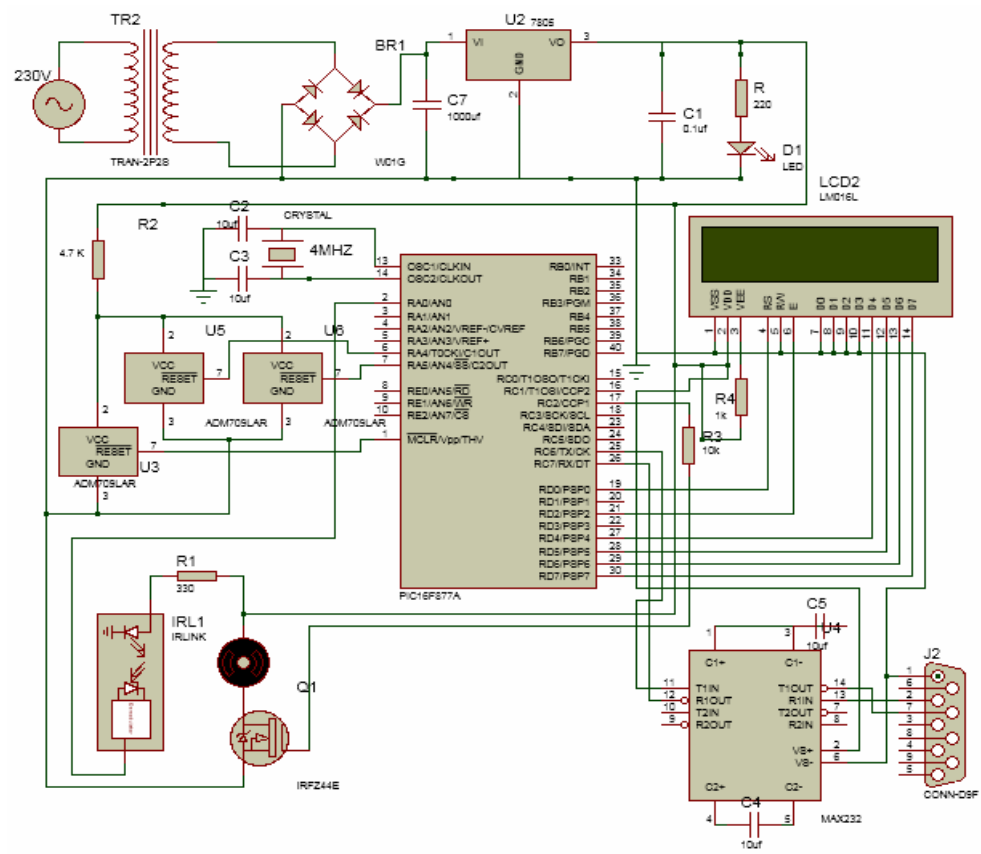

Figure 2. Circuit diagram of embedded fuzzy DC motor control

\section{Fuzzy Variables}

The three variables are given to fuzzy algorithm viz. 'error' and 'change in error' as input and 'PWM' as an output. These variables and their equation with partitions are shown in Table 1.

Table 1. Fuzzy Variables

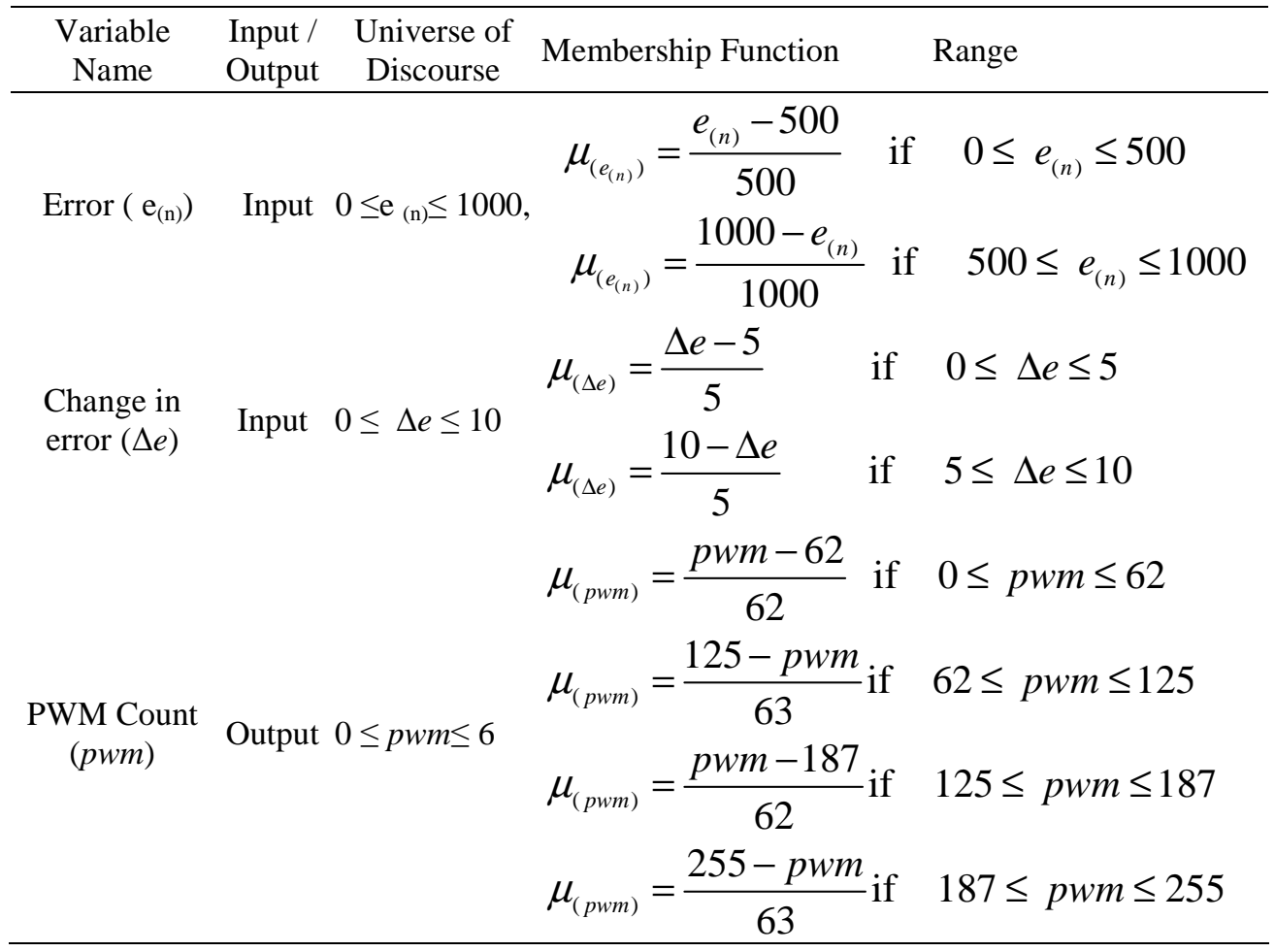

4.1 Fuzzification of signals 'error $\left(e_{(n)}\right)$ ', 'change in error $(\Delta \mathrm{e})$ ' and ' $P W M$ ':

Fuzzification is the process of changing a real scalar value into a fuzzy degree of membership. This is achieved by the triangular membership function. The triangular membership function is the simple and easy for fuzzy algorithm. The 'error' signal range is 0-1000, partitioned into two triangular membership function entitled as Low and High. $\omega_{1}$ and $\omega_{2}$ are the degrees of membership 
function as shown in Figure 3. The fuzzification of 'change in error' signal is similar to 'error' signal except range and labels as shown in Figure 4.

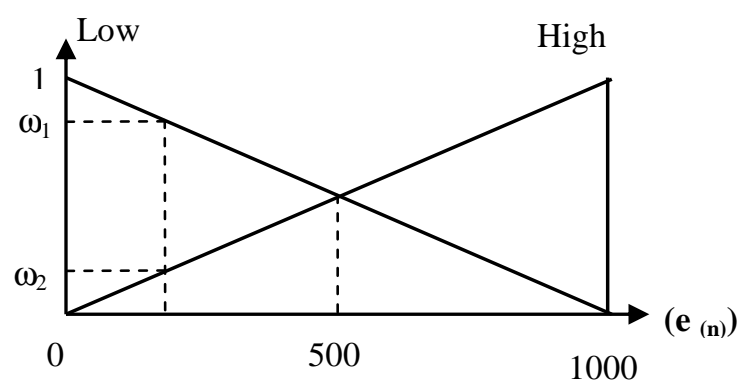

Figure 3. Fuzzification of 'error $\left(\mathrm{e}_{(\mathrm{n})}\right)$ ' signial

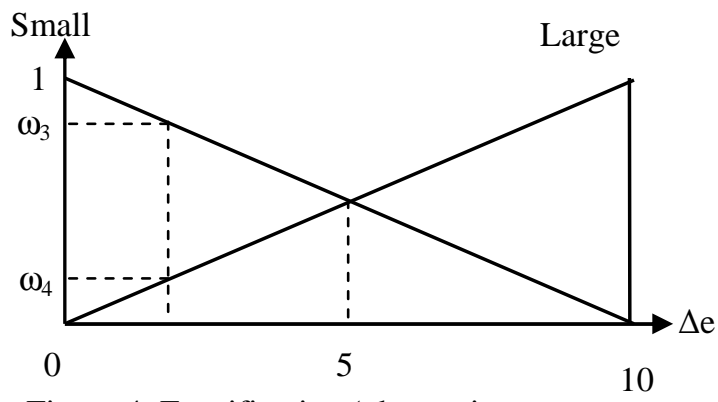

Figure 4. Fuzzification 'change in erroı $(\Delta \mathrm{c})$ sıgnal

4.2 Fuzzification PWM count signal:

The PWM fuzzification signal is partitioned into four regions entitled as Increase, Mentain-1, Mentain-2 and Decrease. The range of fuzzification of binary counts signal is from 0 to 255 , which is shown in figure 5 .

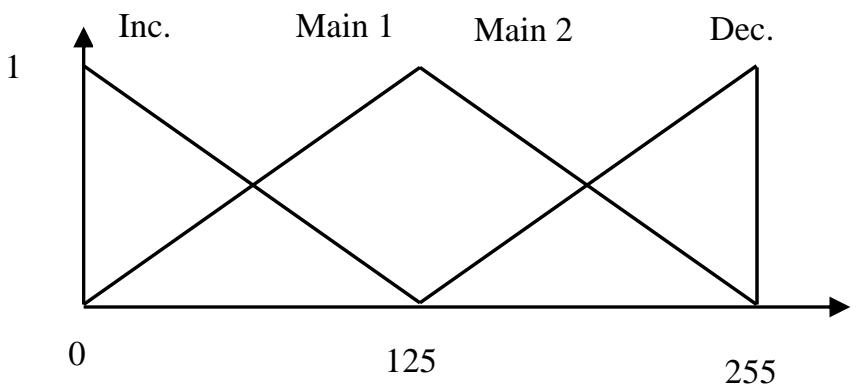

Figure 5. Fuzzification of binary count signal

The PWM count is divided into four triangular shaped membership functions. Labels and ranges of the membership functions are shown in table 2 .

Table 2. Name and range of output membership function

\begin{tabular}{|c|c|c|}
\hline Obs. no. & $\begin{array}{c}\text { Name of the output } \\
\text { membership function }\end{array}$ & $\begin{array}{c}\text { Range of output membership } \\
\text { function in binary count }\end{array}$ \\
\hline 1 & Dec & $0-63$ \\
\hline 2 & Main-1 & $63-126$ \\
\hline 3 & Main-2 & $126-192$ \\
\hline 4 & Inc & $192-255$ \\
\hline
\end{tabular}

\subsection{Fuzzy Inference System:}

Mamdani's fuzzy inference method is simple hence, it is commonly used in fuzzy methodology. It is combining fuzzified inputs according to the fuzzy rules to establish a rule strength. Finding the consequence of the rule by combining the rule strength and the output membership function and combining the consequences to get an output distribution completes the fuzzy inference process. Fuzzy Inference system is rule based system which comprising the IF-THEN format. The motor drive control knowledge is structured in form of fuzzy IF-THEN rules as shown in table 3. With reference to input signals, 'error' and 'change in error' the PWM count fuzzy logically inferred. 
Table 3. Fuzzy rules

\begin{tabular}{|c|c|c|}
\hline $\begin{array}{ll}\operatorname{Error}\left(e_{(n)}\right) & \text { CIe }(\Delta e) \\
\end{array}$ & Small & Large \\
\hline Low & Maintain-2 & Increase \\
\hline High & Decrease & Maintain-1 \\
\hline
\end{tabular}

\section{Fuzzy Code Implementation}

The advanced electronics technology offers wide spectrum of target microcontrollers for embedding the fuzzy logic control routines. PIC microcontroller has 10-bit ADC with $4.882 \mathrm{mV}$ resolution which has $5 \mathrm{~V}$ supply voltage. Notice that the ADC varies each step after variation of $4.882 \mathrm{mV}$, hence maximum count of ADC is 1024 . Causing we have selects the range of input fuzzification signal 'error (e(n))' is 0 to 1000. The possible range of 'change in error' is less therefore has selects the range of input fuzzification signal change in 'error $(\Delta \mathrm{e})$ ' is 0 to 10 . After generation of PWM it is stored into CCPR1L register of PIC microcontroller which is 8-bit hence selects the range of output fuzzification signal PWM is 0 to 255. During making of C- code, for 'error' signal the defined integer is $\mathrm{x}$ and for 'change in error' signal the defined integer is y. Similarly, for PWM the defined integer is V. W1 and W2, are the degrees of membership for 'error' signal and W3, and W4 are the degrees of membership for change in 'error' signal. 'A' is the defuzzified value that determines the PWM of PIC microcontroller. According to the first fuzzy inference rule (IF 'error' is low and 'change in error' is small THEN PWM is maintain-2), when the value of $\mathrm{x}$ is between 0 to 500 $(\mathrm{x}>=0 \quad \& \& \mathrm{x}<=500)$ and the value of $\mathrm{y}$ is between 0 to $5(\mathrm{y}>=0 \quad \& \& \mathrm{y}<=5)$ then gets the value of PWM using formula $\mathrm{v}$ $=((126 * w 2)+(192 * w 1)) /(w 1+w 2)$. The code of the fuzzy algorithm wherein four rules are written as is shown in figure 6.

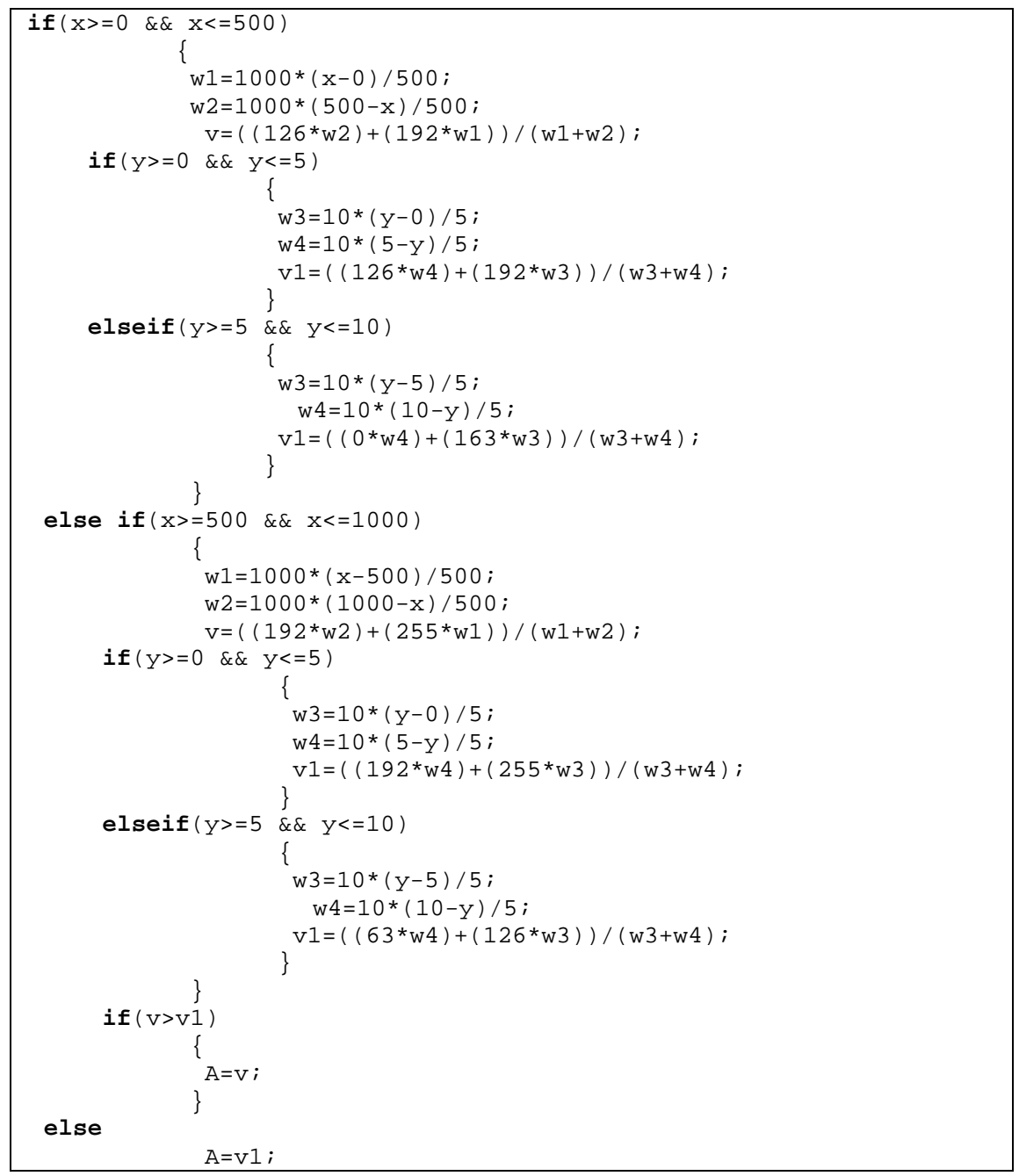

Figure 6. Embedded C-code listing 
In program flow of fuzzy based DC motor control, initially have to select the value of data direction register then initialize the LCD and ADC. The inputs ADC signal and set point signal are calibrated. After calibration, calculate the 'error (x)' between set point RPM (S) and current RPM (R) of DC motor. This 'error' signal is applied to fuzzy algorithm as well as same 'error' signal is stored in register as 'stored error (z)'. 'Change in error (y)' is the difference between 'stored error (x1)' and 'error (x)' which is applied to fuzzy algorithm also. Obtained PWM using fuzzy inference rule is applied to gate of MOSFET as well as LCD for display as shown in Figure 7.

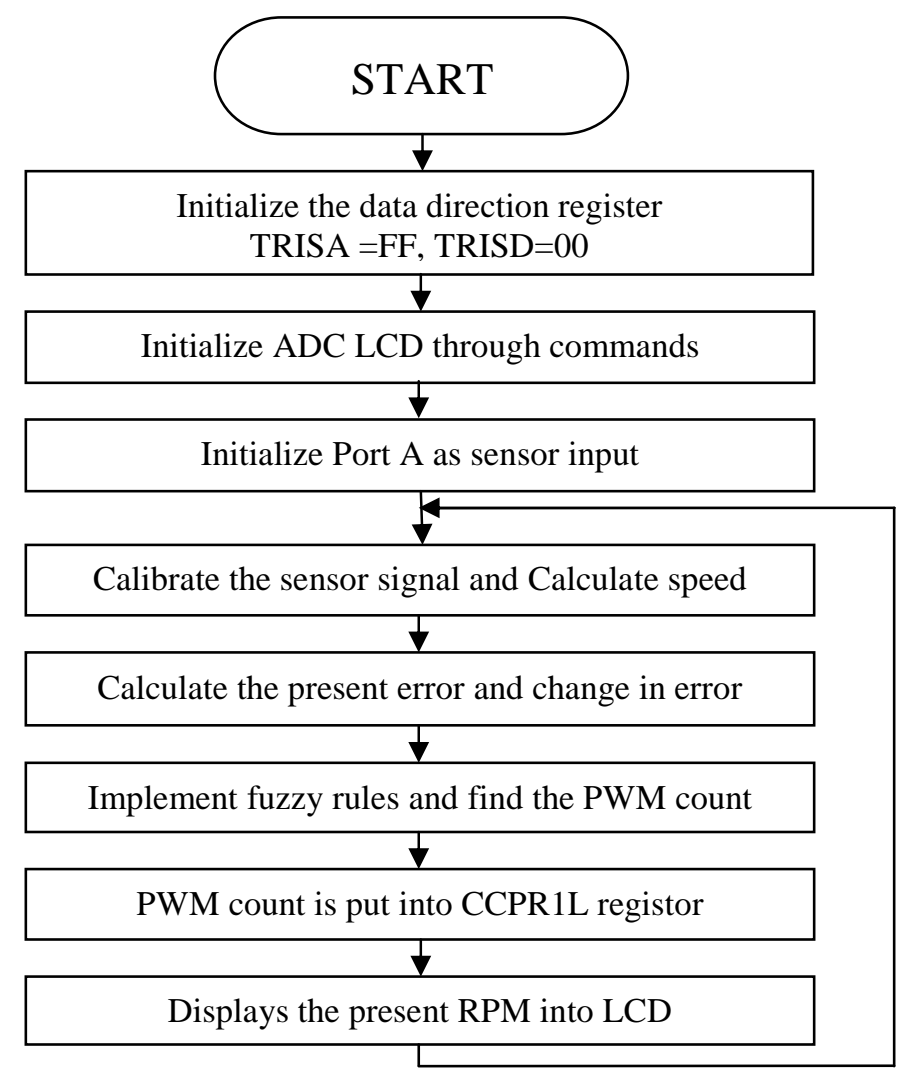

Figure 7. Program flow of DC motor control

The fuzzy algorithm based code is embedded into PIC 16f877A microcontroller and then this IC is used in circuit. The optoisolator sensor module, motor driver FET, max 232 and $2 \times 16$ LCD are interfaced to PIC microcontroller. The hardware implementation photo snap is shown in figure 8.

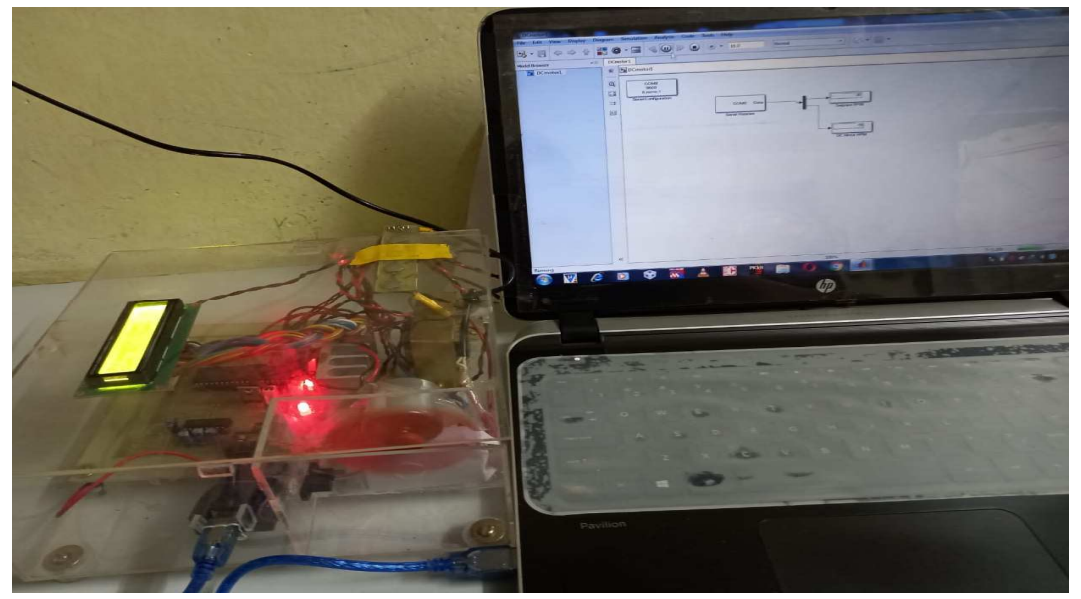

Figure 8. Hardware implementation image 


\section{Result and Discussion}

The set point RPM have been applied to microcontroller through keypad and RPM of DC motor has measured through optoisolator sensor module. The microcontroller finds the difference between set point RPM and DC motor RPM which is first input of fuzzy algorithm. The microcontroller also finds the difference between current error and previous error entitled as 'change in error' while it have applied to fuzzy algorithm as second input. The fuzzy algorithm is embedded in PIC 16F877A microcontroller wherein two input fuzzification signals 'error $\left(\mathrm{e}_{(\mathrm{n})}\right)$ ' and 'change in error $(\Delta \mathrm{e})$ ' and one output fuzzification signal PWM. The varied 'error' signal and 'change in error' signal with obtained outputs are shown in Table 4. The one input fuzzification signal 'error' has been increases and another input fuzzification signal 'change in error' has varied randomly and then recorded the count of PWM. If input fuzzification signals 'error' and 'change in error' tries to increase or decrease then fuzzy algorithm controls the PWM and maintains the speed of DC motor which is equivalent to set point.

Table 4. The input and output fuzzification signals

\begin{tabular}{|c|c|c|c|c|}
\hline $\begin{array}{c}\text { Sr. } \\
\text { No. }\end{array}$ & $\begin{array}{c}\text { Input fuzzification } \\
\text { signal } \\
\left(\text { Error }\left(e_{(n)}\right)\right)\end{array}$ & $\begin{array}{c}\text { Input fuzzification } \\
\text { signal } \\
(\text { Change } \text { in error }(\Delta e))\end{array}$ & $\begin{array}{c}\text { Output fuzzification } \\
\text { signal } \\
(\boldsymbol{P W M})\end{array}$ & $\begin{array}{c}\text { Motor Speed } \\
(\mathbf{R P M})\end{array}$ \\
\hline 1. & 2 & 0.1 & 162 & 810 \\
\hline 2. & 6 & 1.5 & 163 & 812 \\
\hline 3. & 10 & 0.15 & 161 & 805 \\
\hline 4. & 19 & 0.4 & 160 & 797 \\
\hline 5. & 52 & 0.5 & 157 & 781 \\
\hline 6. & 100 & 0.8 & 152 & 665 \\
\hline 7. & 302 & 0.3 & 133 & 587 \\
\hline 8. & 500 & 1.0 & 117 & 560 \\
\hline 9. & 700 & 6 & 112 & 518 \\
\hline 10. & 800 & 9 & 104 & 612 \\
\hline 11. & 900 & 3.3 & 122 & 283 \\
\hline 12 & 1000 & 9 & 57 & \\
\hline
\end{tabular}

The 'error' and 'change in error' signal is applied to fuzzy algorithm and obtains the appropriate PWM. This obtained PWM is applied to motor driver and recorded the speed of DC motor. Figure 9 shows the plot between motor RPM and output of fuzzy algorithm PWM. The PWM and RPMs are directly proportional to each other because Speed of DC motor is depends on PWM.

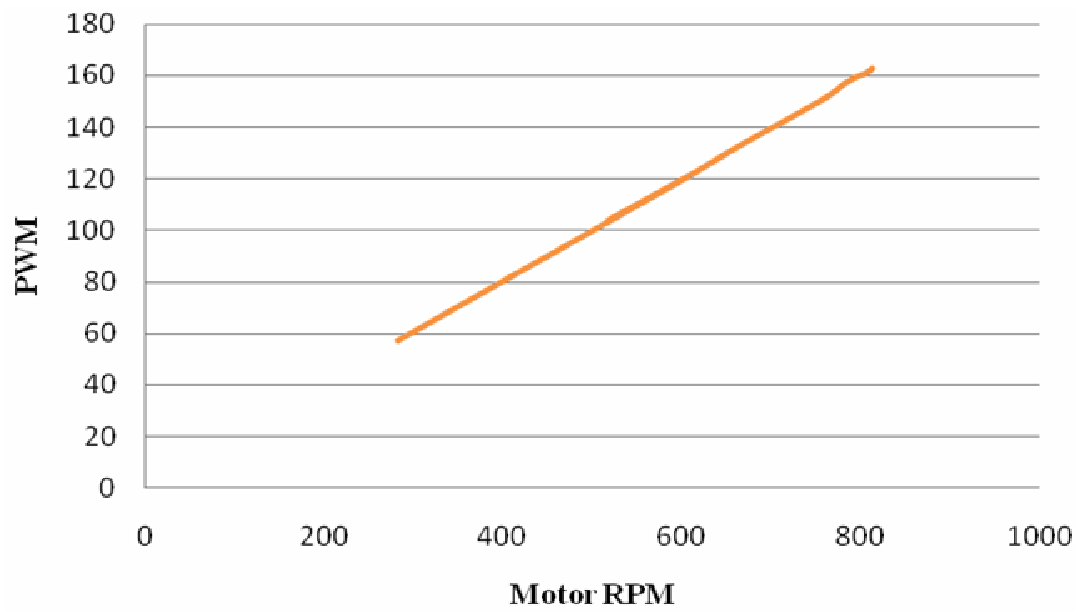

Figure 9. Graph between DC motor RPM and PWM

The microcontroller has been programmed for fuzzy PWM generation based on the set point RPM and measured RPM signals. The speed of DC motor has depends on variation of current flowing through it. In conformity with PWM, the motor driver controls the current flowing through in motor. With reference to RPM set point the embedded fuzzy algorithm generates appropriate PWM, consequently controls the speed of DC motor. RPM set point 450 have been applied to microcontroller which is depicted as blue 
color line and recorded the motor rotations per minute as shown in figure 10. Causing inductive and magnetic effect of DC motor, the observed RPMs are slightly fluctuated, but approximately equal to the set point. However, it is vicinity of set point as shown in brown color line. The fuzzy algorithm based on microcontroller provided the speed control of dc motor in linear fashion. Fuzzy logic control system is applied to DC motor control application and achieves appropriate RPM of motor because fuzzy logic is operated on the basis human thinking.

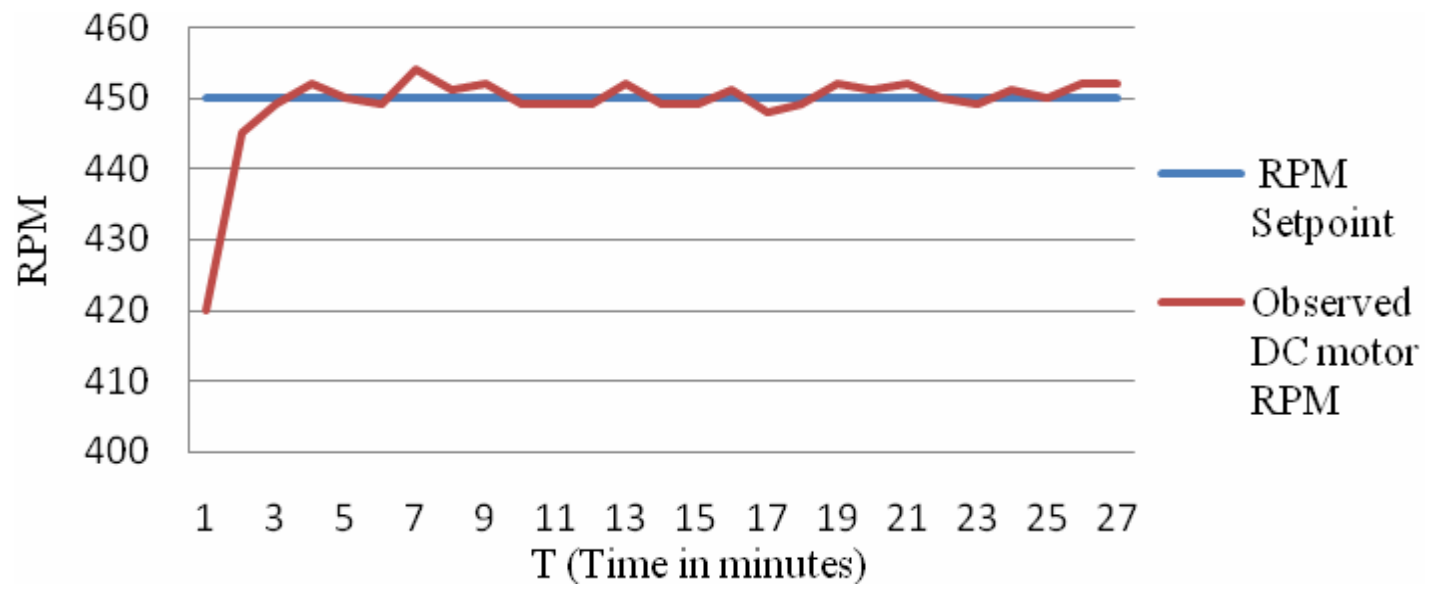

Figure 10. Graph between DC motor RPM and Time

\section{Conclusion}

In DC motor control system, according to set point it is very difficult to achieve the speed of DC motor because magnetic induction of motor. We know that the microcontroller is operated on program logic which provides precise output. In this paper, set points have been provided to microcontroller and achieved the appropriate speed of motor. The fuzzy algorithm is embedded in microcontroller wherein two inputs 'error' and 'change in error' while one output 'PWM'. The newly involved parameter is 'change in error' Due to inputs 'error' and 'change in error, increases the degree of accuracy of fuzzy algorithm hence the obtained motor speeds are more equivalent to set points. If fuzzy algorithm is embedded in the microcontroller, it could be a cost effective solution for industrial process control. If fuzzy-PID and fuzzy type-2 controller are embedded in microcontroller then can be improve the response of motor.

\section{References}

Goel A., Uniyal A., Bahuguna A., Patwal R.S. and Ahmed H., 2012, Performance comparison of PID and fuzzy logic controller using different defuzzification techniques for positioning control of DC motors, Journal of Information Systems and Communication, Vol. 3, pp 235-238.

Harb A.M. and Smadi I.A., 2009, Tracking control of DC motors via mimo nonlinear fuzzy control, Chaos, Solitons and Fractals, Vol. 42, No. 2, pp. 702-710. https://doi.org/10.1016/j.chaos.2009.01.037

Hanamane M.D., Mudholkar R.R., Jadhav B.T. and Savant S.R., 2006, Implementation of fuzzy temperature control using microprocessor, Journal of Scientific and Industrial Research, Vol. 65, pp.142-147.

Lim C.M., 1995, Implementation and experimental study of a fuzzy logic controller for dc motors, Computers in Industry, Vol. 26, No. 1, pp. 93-96. https://doi.org/10.1016/0166-3615(95)80009-3

Meha S.A., Haziri B., Gashi L.N., Fejzullahu B., 2011, Controlling DC motor speed using PWM from C\# windows application, In Proceedings of $15^{\text {th }}$ International Research/Expert Conference "Trends in the Development of Machinery and Associated Technology", TMT 2011, Prague, Czech Republic, pp. 481-484.

Nanda A, Crow M.L., 1995, An energy based approach to under voltage load shedding, Electric Power Systems Research, Vol. 32, pp. 11-18. https://doi.org/10.1016/0378-7796(94)00890-G

Pravadalioglu S., 2005, Single-chip fuzzy logic controller design and an application on a permanent magnet dc motor, Engineering Applications of Artificial Intelligence, Vol. 18, No. 7, pp. 881-890. https://doi.org/10.1016/j.engappai.2005.03.004

Ramadan E.A.M., El-Bardini M., El-Rabaie N.M., Fkirin M.A., 2014, Embedded system based on a real time fuzzy motor speed controller, Ain Shams Engineering Journal, Vol. 5, No. 2, pp. 399-409. https://doi.org/10.1016/j.asej.2013.10.001

Yan W., Wang D., Ji P. and Li W., 2012, The PWM speed regulation of DC motor based on intelligent control, Engineering Procedia, Vol. 3, Pp.259 - 267. https://doi.org/10.1016/j.sepro.2011.11.028

Zadeh L. A., 1965, Fuzzy sets, Information and Control, Vol. 8, pp. 338-353. https://doi.org/10.1016/S0019-9958(65)90241-X 


\section{Biographical notes}

K.D. Atar received M.Sc. in 2011 in Electronics science with embedded system specialized and Ph.D. degree in 2016 from Shivaji University Kolhapur, India. He has qualified SET and NET also. He has published 13 international and 2 national journal papers. He has also presented more than 20 research articles in national and international conferences.

C. B. Patil is with the Department of Electronics, D. K. A. S. C. College, Ichalkaranji, Maharashtra, India while R. R. Mudholkar is with the Department of Electronics, Shivaji University, Kolhapur, Maharashtra, India 